\title{
Paleomagnetism of the Devonian Onondaga Limestone Revisited
}

\author{
DenNis V. Kent \\ Lamont-Doherty Geological Observatory of Columbia University \\ Palisades, New York 10964
}

\begin{abstract}
Ninety-six oriented samples were collected from 13 sites in the Onondaga limestone of New York for paleomagnetic study, including rock magnetism and magnetic susceptibility anisotropy. The sites were located in a small penecontemporaneous fold and a larger fold of imprecisely known origin, as well as flatlying beds. The natural remanent magnetizations (NRM) give directions (declination $195.1^{\circ}$, inclination $84.4^{\circ}$, and $\alpha_{0 s}=6.9^{\circ}$ for $N=13$ sites) that are similar to those originally measured for the Onondaga limestone by Graham (1956). Alternating field and thermal demagnetization analyses show that the NRM is a composite of a large viscous component along the present geomagnetic field and a smaller, more stable component of magnetization with a shallow and southerly direction. The site mean directions after 300 Oe of magnetic cleaning, but without correction for bedding tilt, give a formation mean of declination $168.7^{\circ}$, inclination $13.6^{\circ}$, and $\alpha_{06}=8.3^{\circ}$ for $N=9$ sites (the magnetizations at four sites could not be adequately resolved and are omitted). Although the stable magnetization is shown to be of postfolding origin, essentially the same direction is obtained at sites with flat-lying bedding as at the sites with folded bedding prior to tilt correction. Rock magnetic investigations indicate that some form of magnetite is the important magnetic mineral in the limestone. The similarity in magnetic fabric between a small penecontemporaneous fold and a larger fold suggests acquisition of magnetic properties while the sediment was still unconsolidated. The postfolding origin of stable remanence is therefore interpreted as a form of postdepositional detrital remanent magnetism. The paleomagnetic pole position derived from the formation mean direction is located at latitude $39.7^{\circ} \mathrm{N}$, longitude $120.7^{\circ} \mathrm{E}\left(d p=4.3^{\circ}, d m=8.5^{\circ}\right)$ and agrees reasonably well with other Devonian poles from cratonic North America, although a Permian age for the magnetizations of the Onondaga cannot be entirely discounted.
\end{abstract}

\section{INTRODUCTION}

Limestones were the subject of study early in the history of paleomagnetic research on sedimentary rocks, and the results have figured prominently in discussions of the early Paleozoic paleomagnetic field for North America. Of particular interest are the pioneering paleomagnetic studies of J. W. Graham on two limestone units in the Appalachians, the Ordovician Trenton limestone and the Devonian age Onondaga limestone [Graham, 1954; 1956]. Both the Trenton and the Onondaga limestones gave well-clustered remanent magnetic directions that dipped steeply down and toward the south, away from the present earth's magnetic field at the sampling localities. These characteristics suggested a high degree of stability for a magnetization of ancient origin, possibly from the time of deposition.

Few other paleomagnetic results from the lower Paleozoic of North America were available for a period of time following these reports. Because of this and despite the lack of demagnetization analyses, Graham's results from the Trenton and Onondaga limestones were considered by some, even relatively recently, as being representative of the lower Paleozoic of North America, implying a near-polar position during this time [e.g., Creer, 1970]. The situation has since changed, and many new data and analytical techniques are available that require a reassessment of some of the older results. McElhinny and Opdyke [1973] resampled the same section of the Trenton limestone that was studied originally by Graham. Although initial measurements also gave steeply inclined remanent directions, the stable component isolated after partial thermal or alternating field demagnetization had a shallow and southerly direction. The shallow direction was attributed to a record of the Ordovician paleomagnetic field, and this conclusion is supported by subsequent studies of other Ordovician formations from North America [e.g., Van der Voo and French, 1977].

Copyright (C) 1979 by the American Geophysical Union.
Shallow remanent inclinations also appear to be characteristic of more recent paleomagnetic studies of various Devonian age rocks from North America, including limestones from Ohio [Martin, 1975] and red beds in New York [Kent and Opdyke, 1978]. These results imply near-equatorial paleolatitudes for North America, in accordance with paleoclimatic evidence but in contrast with the near-polar paleolatitudes implied by the steep remanent inclinations found in the Onondaga limestone. In light of these developments a renewed paleomagnetic investigation of the Onondaga limestone was undertaken and is reported here.

\section{Geological SetTing and SAMPLing}

The Onondaga limestone is a gray-colored, predominantly fine-grained limestone that extends from Ontario, Canada, south to West Virginia. The formation thickens eastward from about 70 feet $(21 \mathrm{~m})$ in the type area near Syracuse, New York, to over 100 feet $(30 \mathrm{~m})$ in the Helderberg area in the Hudson River Valley, and to about 200 feet $(61 \mathrm{~m})$ southward, in northeastern Pennsylvania [Oliver et al., 1962]. Some age variation over this large area is probable, but in New York, where samples for Graham's and for this study were obtained, the Onondaga limestone is generally considered to be of Eifelian (early Middle Devonian) age [Oliver, 1960].

A total of 96 oriented paleomagnetic samples were drilled at 13 sites distributed over the Onondaga outcrop from Syracuse, east to the Helderbergs, and south to the Catskill front (Figure 1). Eight of the 13 sites are in essentially flat-lying beds: four sites ( $E, F, G$, and $\mathrm{H}$ (Figure 1$)$ ) at the Onondaga Indian Reservation Quarry near Syracuse and two sites (UA and UB) at the Ulster County Quarry near Kingston. Two sites (B and LC) in flat-lying beds are at localities where the Onondaga limestone is also deformed. At the Clarksville, New York, locality, there are structures exposed which according to $R u d d$ [1955] (and quoted by Graham [1967, p. 633]) were generated by penecontemporaneous deformation. This is based on the observation that the overlying and underlying beds of Onon- 


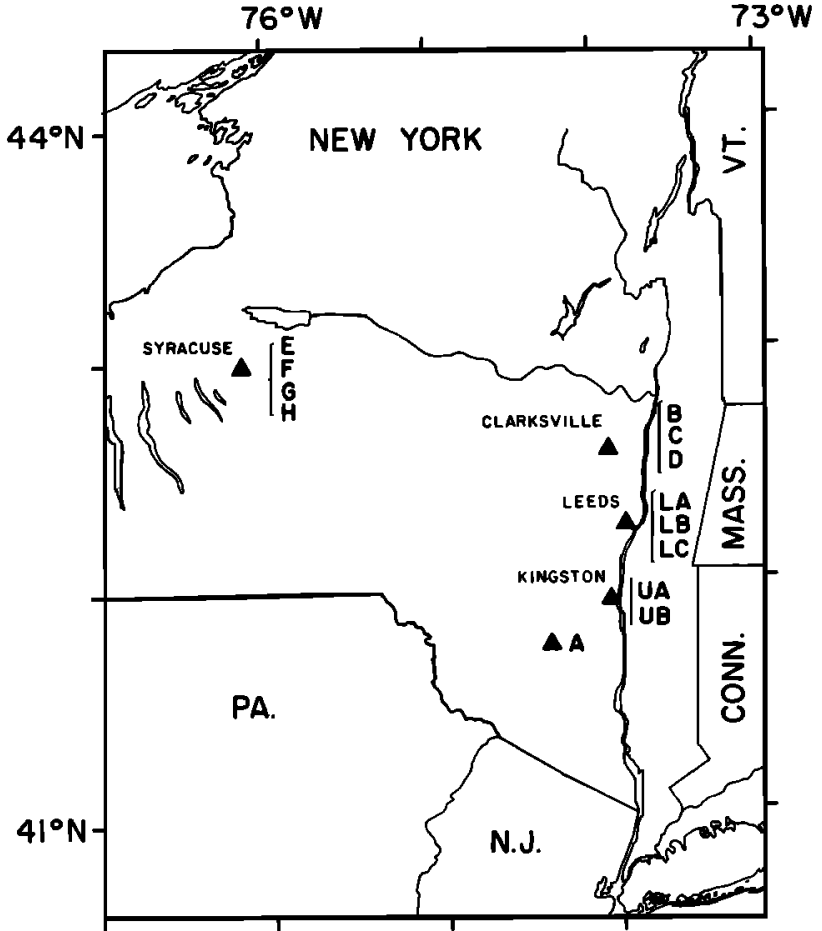

Fig. 1. Location of sampling sites of Onondaga limestone in New York State.

daga limestone are not deformed and although the matrix shows signs of extensive flowage and bending, the enclosed hard, brittle bryozoans and branching coral fossils seem undistorted. A small fold about $1 \mathrm{~m}$ across was sampled, a site (C and $D$ ) in each limb, and is the same fold that was previously sampled by Graham [1956, 1967]; samples from the underlying flat-lying beds are included as site $\mathrm{C}$. At the sampling locality in Leeds Gorge the Onondaga is exposed in a tight, northeastsouthwest trending syncline. The syncline, about $50 \mathrm{~m}$ across, is asymmetric with the eastern limb standing near vertical, while the western limb dips at about $45^{\circ}$ to the east. Stratigraphically distributed samples were taken from the more than
$30 \mathrm{~m}$ of exposed Onondaga; these samples were divided into two sites (LA and LB), each representing a limb of the fold. Flat-lying beds were sampled about $100 \mathrm{~m}$ upstream from the axis of the fold and are included as site LC. The reason for sampling at these two localities was to apply a fold test and to compare the magnetizations in folds of different sizes and presumably of different origins. Finally, one site (A) was occupied in beds uniformly dipping to the west that are exposed in an abandoned quarry near Warwarsing (Figure 1).

\section{Paleomagnetism}

\section{Natural Remanent Magnetization}

The direction and intensity of natural remanent magnetization (NRM) of standard specimens cut from the 96 individually oriented samples were measured with a computerized 7$\mathrm{Hz}$ flux-gate spinner magnetometer [Molyneux, 1971]. The NRM are of weak to moderate intensity, averaging $3.5 \times 10^{-6}$ $G$, but are readily measured. The site mean NRM directions are plotted in Figure 2, and the site statistics given in Table 1. The directions are steeply inclined down and group closely about a mean of declination $195.1^{\circ}$, inclination $84.4^{\circ}, k=36.8$ and $\alpha_{95}=6.9^{\circ}$ for $N=13$ sites. This is very near to the mean NRM direction (declination $177^{\circ}$, inclination $79^{\circ}, k=19$, and $\alpha_{96}=4^{\circ}$ ) calculated by Cox and Doell [1960] from Graham's [1956] measurements of 65 samples collected from two localities in the Onondaga limestone. The strata are appreciably tilted at several of the sites; correction for the bedding tilt results in an increased scatter in the site mean NRM directions (Figure $2 b$ ) and implies that the NRM originates from some time after the beds were folded, as Graham previously noted.

\section{Alternating Field Demagnetization}

The remanent magnetization of each sample was remeasured after each successive alternating field (af) demagnetization treatment in peak fields of 100,200 , and $300 \mathrm{Oe}$. The change in remanent intensity with higher alternating fields was uniformly alike for all samples: There is a large decrease to one half and less of the initial value after $100 \mathrm{Oe}$, and less than one third of the original NRM intensity typically remains after 300 Oe. In samples from all but four of the sites the decrease in

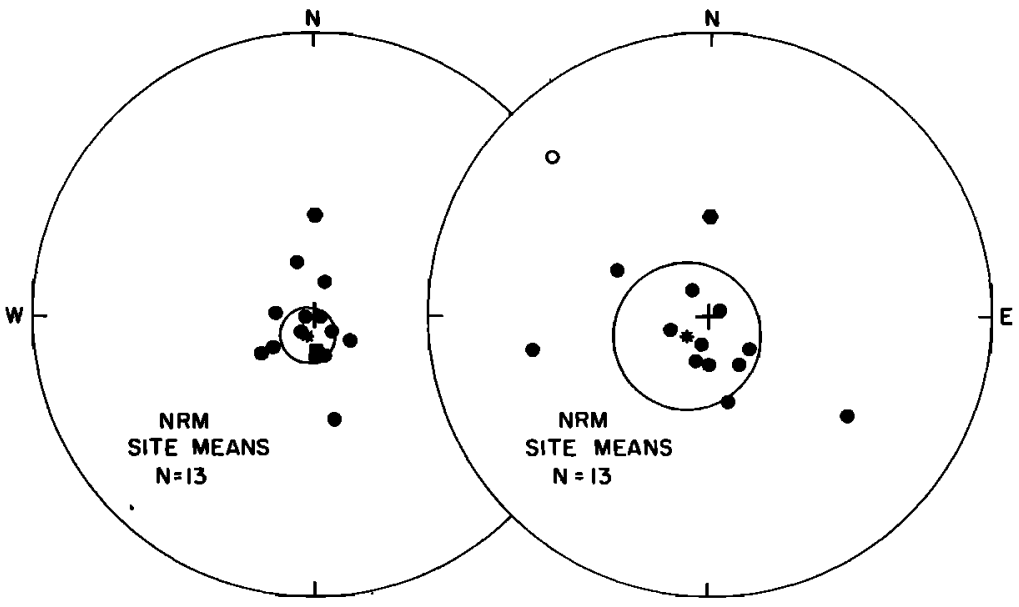

(a) GEOGRAPHIC

(b) BEDDING

Fig. 2. Site mean NRM directions for Onondaga limestone $(a)$ before and $(b)$ after correction for bedding attitude. Solid (open) symbols are plotted on the lower (upper) hemisphere of equal-area projections. Hexagons represent the direction of the present geomagnetic dipole field for the sampling region. Stars represent the formation mean NRM direction enclosed by the circle of $95 \%$ confidence. Shown for comparison by the square in Figure $2 a$ is the mean NRM direction for Onondaga limestone calculated by Cox and Doell [1960] from the original data plotted by Graham [1956]. 
TABLE 1. Statistics of Site Mean Directions of Magnetization of Onondaga Limestone

\begin{tabular}{|c|c|c|c|c|c|c|c|c|c|}
\hline & \multirow[b]{3}{*}{$N$} & \multicolumn{3}{|c|}{ NRM, deg } & \multicolumn{5}{|c|}{$300-O e$ af, deg } \\
\hline & & \multicolumn{2}{|c|}{$\begin{array}{l}\text { Before Tilt } \\
\text { Correction }\end{array}$} & \multirow[b]{2}{*}{$\alpha_{\theta B}$} & \multicolumn{2}{|c|}{$\begin{array}{l}\text { Before Tilt } \\
\text { Correction }\end{array}$} & \multirow[b]{2}{*}{$\alpha_{06}$} & \multicolumn{2}{|c|}{$\begin{array}{l}\text { After Tilt } \\
\text { Correction }\end{array}$} \\
\hline & & $\begin{array}{c}\text { Declina- } \\
\text { tion }\end{array}$ & $\begin{array}{c}\text { Inclina- } \\
\text { tion }\end{array}$ & & $\begin{array}{l}\text { Declina- } \\
\text { tion }\end{array}$ & $\begin{array}{l}\text { Inclina- } \\
\text { tion }\end{array}$ & & $\begin{array}{l}\text { Declina- } \\
\text { tion }\end{array}$ & $\begin{array}{c}\text { Inclina- } \\
\text { tion }\end{array}$ \\
\hline $\begin{array}{c}\text { Site } \\
\text { LA } \\
\text { LB } \\
\text { LC } \\
\text { UA } \\
\text { UB } \\
\text { A } \\
\text { B } \\
\text { C } \\
\text { D } \\
\text { E } \\
\text { F } \\
\text { G } \\
\text { H } \\
\text { Mean } \\
\text { Mean* }\end{array}$ & $\begin{array}{r}20 \\
19 \\
6 \\
5 \\
9 \\
5 \\
5 \\
4 \\
4 \\
5 \\
4 \\
5 \\
5 \\
13 \\
9\end{array}$ & $\begin{array}{r}143.3 \\
125.7 \\
175.5 \\
169.8 \\
232.4 \\
135.8 \\
165.1 \\
271.3 \\
232.8 \\
341.6 \\
256.2 \\
216.1 \\
18.1 \\
195.1\end{array}$ & $\begin{array}{l}86.2 \\
76.9 \\
79.2 \\
59.1 \\
75.4 \\
82.5 \\
78.5 \\
78.7 \\
70.9 \\
74.0 \\
87.9 \\
83.5 \\
79.7 \\
84.4\end{array}$ & $\begin{array}{r}5.4 \\
5.6 \\
9.8 \\
26.5 \\
12.6 \\
20.2 \\
15.3 \\
6.8 \\
21.6 \\
8.5 \\
16.8 \\
18.1 \\
15.1 \\
6.9\end{array}$ & $\begin{array}{r}174.5 \\
165.4 \\
158.9 \\
172.7 \\
174.8 \\
165.3 \\
170.9 \\
165.0 \\
169.1 \\
350.2 \\
127.9 \\
80.5 \\
27.2 \\
\\
168.7\end{array}$ & $\begin{array}{r}9.3 \\
23.4 \\
41.0 \\
9.4 \\
10.3 \\
9.8 \\
15.2 \\
6.3 \\
-1.0 \\
76.3 \\
70.6 \\
66.4 \\
60.1 \\
\\
13.6\end{array}$ & $\begin{array}{r}8.1 \\
7.0 \\
12.1 \\
15.0 \\
6.8 \\
29.3 \\
22.1 \\
17.1 \\
12.5 \\
16.5 \\
34.6 \\
31.6 \\
33.6 \\
8.3\end{array}$ & $\begin{array}{r}263.1 \\
163.8 \\
160.8 \\
172.5 \\
174.7 \\
177.2 \\
169.7 \\
165.6 \\
172.4 \\
334.8 \\
142.3 \\
99.1 \\
35.2\end{array}$ & $\begin{array}{r}39.1 \\
-14.5 \\
37.8 \\
14.4 \\
15.3 \\
33.6 \\
11.5 \\
-9.7 \\
9.0 \\
83.9 \\
65.1 \\
66.7 \\
67.1\end{array}$ \\
\hline
\end{tabular}

$N$ is the number of samples, $\alpha_{06}$ is the semiangle of the cone of $95 \%$ confidence [after Fisher, 1953]. The paleomagnetic pole position ( $N=9$ sites, $300-O e$ af, before tilt correction) is latitude $=39.7^{\circ} \mathrm{N}$, longitude $=120.7^{\circ} \mathrm{E}\left(d p=4.3^{\circ}, d m=8.5^{\circ}\right), d p$ and $d m$ being the semiaxes of the oval of $95 \%$ confidence around the mean pole position, along and perpendicular to the paleomeridian, respectively.

"Excludes sites E, F, G, and $\mathrm{H}$.

intensity is accompanied by a progressive change in remanent direction from near vertical to southerly and nearly horizontal (Figure 3).

It is not certain whether a single component of magnetization is isolated after af treatment; demagnetization at an alternating field higher than 300 Oe generally results in very weak magnetization, and the acquisition of spurious components during the demagnetizing procedure becomes more evident, giving data of poor reproducibility. However, there is usually little change in the remanent direction from the 200- to 300-Oe af treatments, and the directions after 300-Oe af may therefore approximate stable endpoints.

The af demagnetization characteristics of the NRM of samples from four sites ( $E, F, G$, and $H$ ) differ in that the directions remain near vertical with little overall change from their NRM orientation, despite the large reduction in remanent intensities with af treatment (Figure 4). The site mean directions after 300 Oe for these four sites tend to group about a near-vertical direction, but the consistency of the directional data from the individual sites is generally poor, as is shown by the large circles of confidence (Figure 4, Table 1).

Using the same criterion for identification of stable endpoints as for the sites which gave shallow directions, the steeply inclined 300-Oe directions from these four sites might be considered to have paleomagnetic significance. However, the large within-site directional scatter after af demagnetization makes the reliability of such an analytical procedure tenuous at these sites, as is clearly demonstrated by detailed thermal demagnetization analysis.

\section{Thermal Demagnetization}

Although the majority of the samples were subjected to af demagnetization treatement, a set of specimens was available for thermal demagnetization analysis and other studies of NRM properties; characteristic thermal demagnetization diagrams are shown in Figure 5. The thermal demagnetization diagram shown in Figure $5 a$ is representative of results obtained for samples from sites which give shallow, southerly directions after af demagnetization. Two components of magnetization can be resolved: a steep, northerly direction is removed first at temperatures of $200^{\circ}-300^{\circ} \mathrm{C}$, followed by the decay to the origin of a shallow, southerly component. The low blocking temperature component has a direction which generally conforms to the present geomagnetic field at the site locality and is therefore considered to be of recent origin. The shallow, southerly direction persists to temperatures near $500^{\circ} \mathrm{C}$, when the magnetization disappears. Since this direction is essentially the same as that obtained by $300-\mathrm{Oe}$ af treatment, the thermal demagnetization data confirm the univectorial nature of the stable component of magnetization and justify the use of the $300-$ Oe directions as stable endpoints for these sites.

This, however, is not the case for the sites which give the steep directions after af demagnetization. In many of the specimens from these sites, at least two magnetization components can again be distinguished (Figures $5 b$ and $5 c$ ). At temperatures of up to $350^{\circ}-375^{\circ} \mathrm{C}$ a dominant, steeply inclined magnetization is removed. In some specimens this component is initially to the south but then becomes northerly (Figure 5c); a northerly direction for the steeply inclined, low blocking temperature component is clearly evident in the demagnetization diagram shown in Figure $5 b$. We consider this magnetization component to originate in the present geomagnetic field at the site locality with perhaps some contribution from exposure to ambient magnetic fields during storage of the specimens in the laboratory prior to their measurements.

Although only a small fraction of the original NRM remains, a distinct magnetization component which decays linearly to the origin can be resolved in several specimens in the higher temperature range, typically $375-465^{\circ} \mathrm{C}$, of demagnetization (Figures $5 b$ and $5 c$ ). This component has a shallow, southerly direction, near that obtained by either thermal or af 

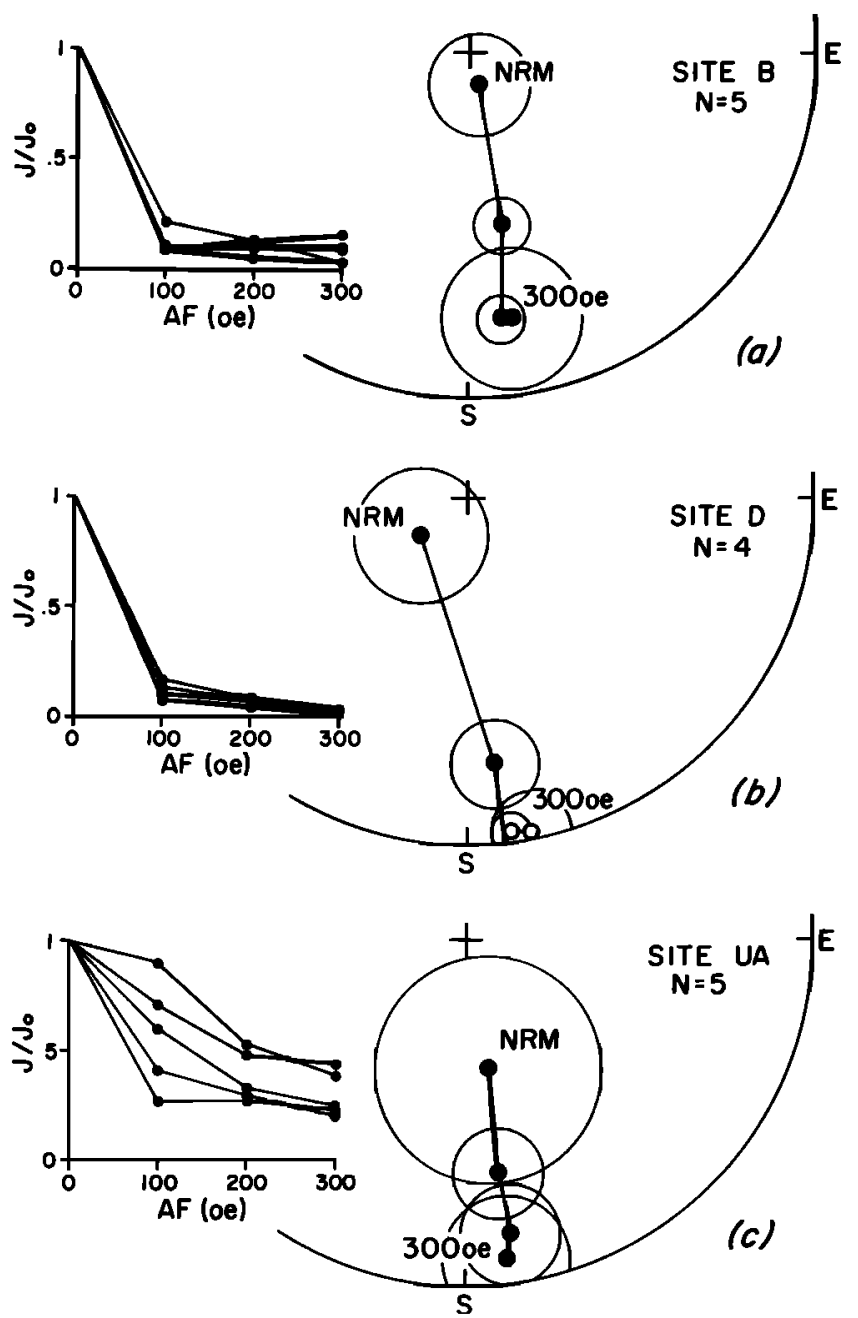

Fig. 3. Site mean directions and associated circles of $95 \%$ confidence of NRM and after af demagnetization at 100,200, and $300 \mathrm{Oe}$ for three sampling sites in Onondaga limestone. Solid (open) symbols are plotted on the lower (upper) hemisphere of equal-area projections. The insets show the decay of NRM intensity of specimens from each site with progressive af demagnetization.

demagnetization from the other sites. These data strongly indicate that the apparently stable vertical directions obtained by af demagnetization at these sites are in fact the resultant of superimposed components of magnetization within each specimen. The two components, one along the present in situ magnetic field and another that has a shallow, southerly direction, apparently have closely overlapping coercivity spectra, since they could not be resolved by af demagnetization. Fortunately, the blocking temperature spectra of the two components were sufficiently distinct in several samples to allow their resolution and identification.

Other samples from these four sites, however, give only a direction along the present magnetic field, and a high blocking temperature magnetization is apparently absent or too weak to detect (Figure $5 d$ ). For this reason and because the magnetization along the present magnetic field could not be effectively removed from most of the samples, these four sites are rejected from further consideration of the paleomagnetism of the Onondaga limestone. We note that similar unreliable paleomagnetic characteristics have been described for Ordovician limestones from Sweden [Claesson, 1978].

\section{Viscous Remanent Magnetization}

The low-coercivity nature of the NRM of the Onondaga limstone suggests that viscous remanent magnetization (VRM) components may be important. To evaluate these, a representative set of samples was exposed to a constant field of 1.0 Oe, and the magnetizations were remeasured at intervals. The samples were either effectively demagnetized (400-Oe af) at the start of the experiment or still had their NRM; both sets of samples, however, behaved similarly over the course of the experiment, as is shown in Figure 6. The acquisition data show appreciable scatter, and viscosity coefficients have not been calculated. Nevertheless, an appreciable increase in magnetization with time is evident to the extent that in all samples the viscous component acquired in the 1.0-Oe field over about 16 months exceeds the original NRM intensity values (Table 2).

The viscous nature of the NRM was also evident by the decrease in the NRM intensities of samples left in field-free space for about 100 hours prior to the VRM acquisition experiments. The NRM of five samples tested decayed to about $25 \%$ of their initial values even over this short time interval. Moreover, the decay corresponded closely in magnitude to the viscous component subsequently acquired by the same samples in a 1.0-Oe field over an equal time interval. We conclude from these experiments that VRM can account for the magnetization along the present earth's magnetic field identified in the thermal demagnetization analyses, which is a significant fraction of the NRM of the Onondaga limestone.

\section{Fold Tests}

As was described earlier, the site mean NRM directions have increased scatter when the bedding is restored to the
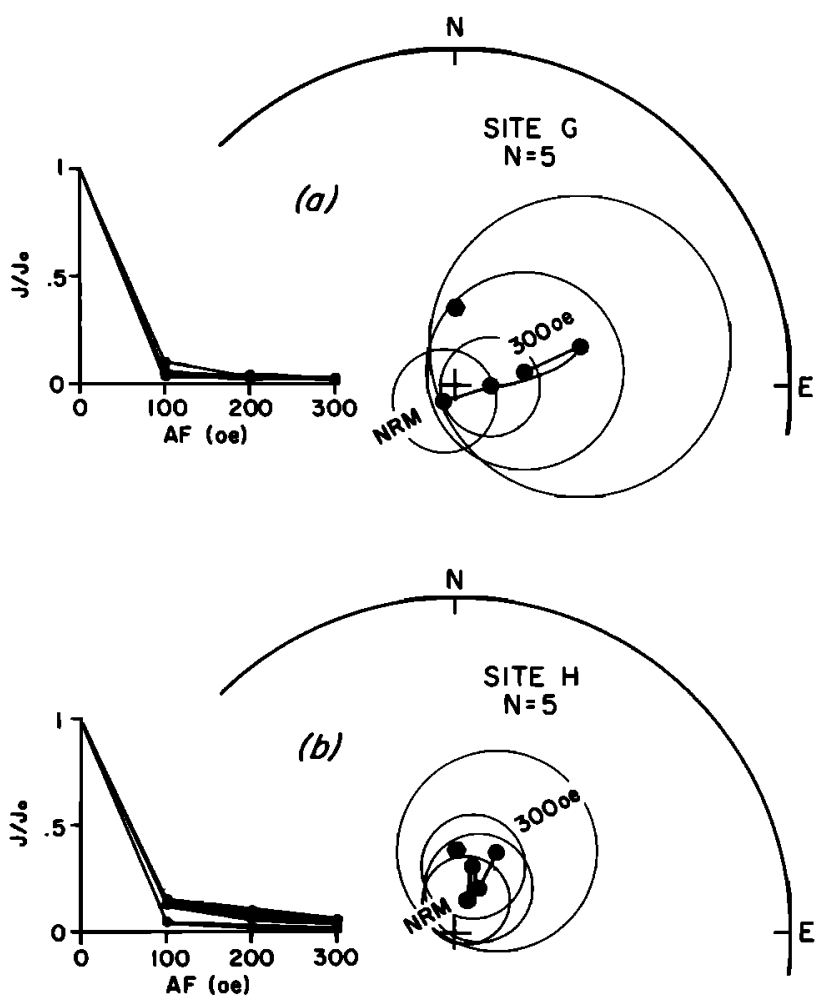

Fig. 4. Site mean directions and associated circles of $95 \%$ confidence of NRM and after af demagnetization at 100,200, and $300 \mathrm{Oe}$ for two sampling sites in Onondaga limestone. Hexagons represent the direction of the present geomagnetic dipole field at the sampling localities. All symbols are plotted on the lower hemisphere of equalarea projections. The insets show the decay of NRM intensity of specimens from each site with progressive af demagnetization. 

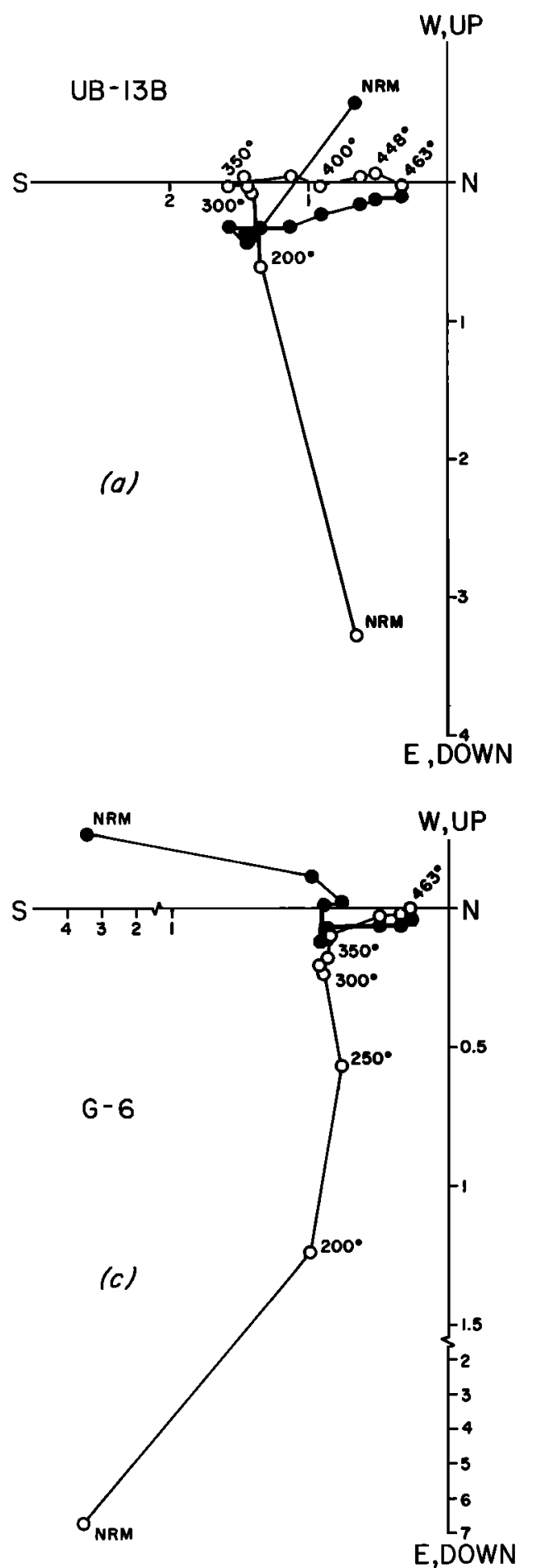
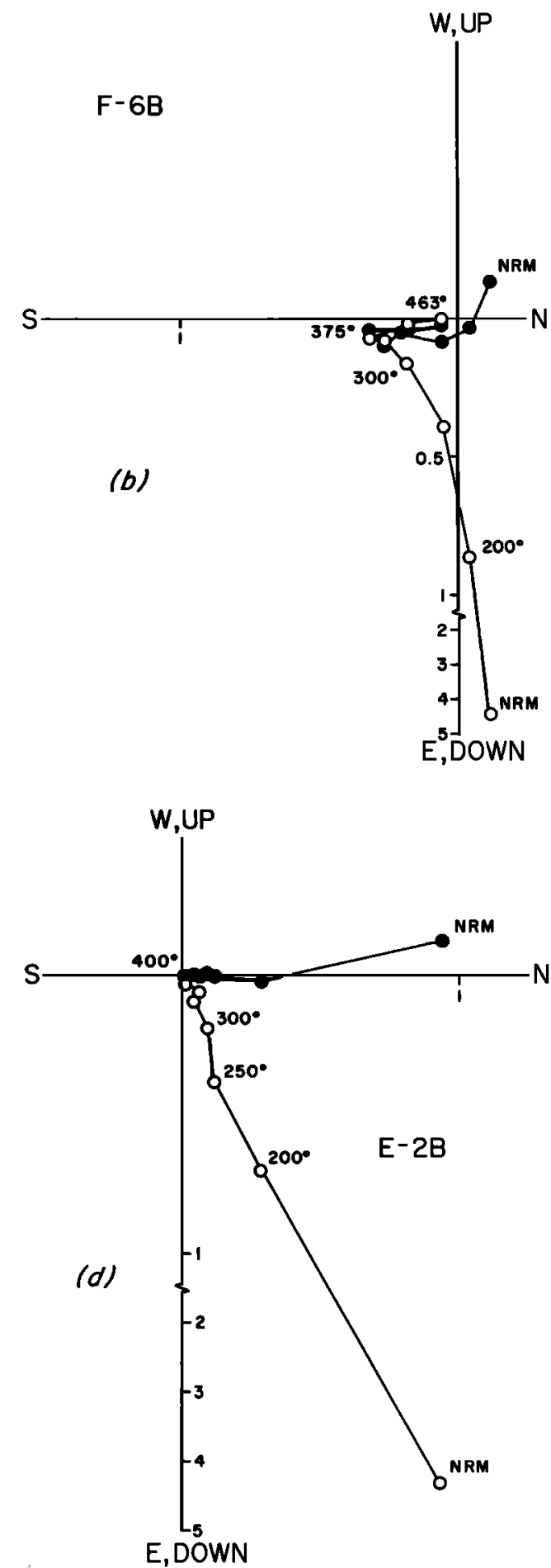

Fig. 5. Thermal demagnetization diagrams for four specimens of Onondaga limestone plotted according to the method of Zijderveld [1967]. The solid symbols represent the remanent magnetization vector endpoints projected onto the horizontal plane, and the open symbols represent the vector endpoints projected onto the N-S vertical plane. One unit on each diagram axis is equal to $1 \times 10^{-8} \mathrm{G}$. Numbers next to selected open symbols are the demagnetization temperatures in degrees Celsius.

horizontal, implying an origin that is postfolding. This is now reasonably accounted for by the NRM consisting of a dominant viscous component of magnetization acquired along the present magnetic field direction long after the beds were folded. However, the stable, shallow directions also become more dispersed when they are corrected for bedding tilt, and therefore this magnetization must also originate from some time during or after folding of the beds. This is clearly in- dicated by negative fold tests obtained from the Clarksville and Leeds Gorge localities (Figure 7). In the small penecontemporaneous fold at Clarksville the value of the precision parameter $k$ decreases from 39.6 to 16.5 when the beds are restored to the horizontal; in the larger synclinal fold at Leeds Gorge, $k$ decreases from 16.8 to 2.2 with unfolding. Using a variance ratio test tabulated by McElhinny [1964], the difference in dispersion (as given by the change in $k$ ) is significantly 


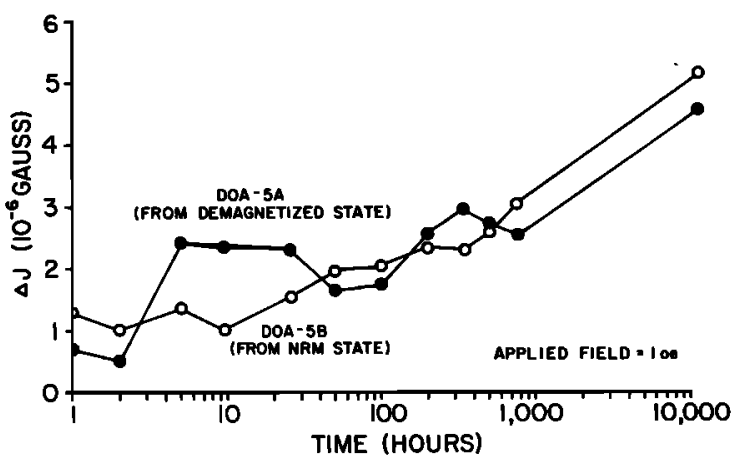

Fig. 6. Test of viscous remanent magnetic properties by the change in remanent magnetization $(\Delta J)$ with time of two companion specimens which were left in a field of 1 Oe for 11,400 hours.

different at the $99 \%$ confidence level for Leeds Gorge, bearing in mind that the test is not strictly valid because the distribution in direction is non-Fisherian after unfolding (Figure 7c). At the Clarksville locality the difference in $k\left(k_{1} / k_{2}=2.40\right)$ is just lower than necessary to be significantly different with unfolding at the $95 \%$ confidence level $\left(N=8\right.$ requires $k_{1} / k_{2}=$ 2.48 [McElhinny, 1964]); this is probably due to the shallower bedding dips of the fold limbs and the small angle between the remanent directions and the fold axis. Despite some statistical uncertainty we nevertheless consider a synfolding or postfolding origin for the stable (300 Oe) magnetizations very likely at both the Clarksville and the Leeds Gorge locality.

\section{Summary}

The site mean directions after 300 Oe for all 13 sites are plotted with respect to the present horizontal (i.e., without correction for bedding tilt) in Figure 8. As was described earlier, the steep directions at four of the sites are due to composite magnetizations that are left unresolved by magnetic cleaning; these sites (small pluses in Figure 8) are omitted from further paleomagnetic analysis. The remainder of the sites $(N=9)$ give directions that are well grouped about a mean of declination $168.7^{\circ}$, inclination $13.6^{\circ}, k=38.8$, and $\alpha_{\theta 5}=8.3^{\circ}$. Although the stable magnetizations can clearly be shown to postdate folding at several site localities, they have essentially the same direction (prior to bedding tilt correction) as at the sites where the beds are flat lying and which show no visible evidence of deformation.

Two sets of well-grouped paleomagnetic directions are therefore found in the Onondaga limestone: the near-vertical NRM and the southerly directions with shallow inclinations obtained after thermal or af demagnetization. It is apparent from detailed demagnetization analyses and the VRM experiments that the vertical directions are primarily the resultant of two different magnetizations: a viscous component along the present field and a more stable component with a shallow, southerly direction. The fraction of the NRM remaining after af demagnetization to $200 \mathrm{Oe}$ is generally of the order of $20 \%$. If the fraction removed $(\sim \mathbf{8 0 \%})$ is considered to represent the vector component along the present field and the fraction remaining that along the mean stable direction given above, then by vector addition a steep direction results as illustrated in Figure 9. This analysis may be overly simplistic in that all of the present-day field component may not be removed at $\mathbf{2 0 0}$ Oe while at the same time, some of the stable magnetization can be carried by coercivities less than 200 Oe. In some of the samples the two components evidently have similar coercivity spectra and cannot be resolved by af demagnetization. Nevertheless, these simple calculations show that an appreciable range of relative contributions from the two component vectors, which is compatible with the range of stabilities observed in the Onondaga, can give resultant directions of magnetizations similar to the measured NRM values (Figure 9).

This leaves the question of the acquisition mechanism responsible for the stable magnetizations with the shallow inclinations and the paleomagnetic significance of these directions. Rock magnetic and magnetic fabric studies that bear on this aspect are described in the next section.

\section{Rock Magnetism}

The interpretation of the origin of stable remanent magnetization in the Onondaga limestone depends critically on the magnetic mineralogy. Thermoremanent magnetization (TRM) or partial TRM due to burial and uplift can be discounted for the Onondaga limestone, since there is no evidence of significant heating since the time of formation. The presence of authigenic magnetic minerals would point to chemical remanent magnetization (CRM) as the controlling remanence acquisition process which if it occurred late in the history of the rocks could also help explain the postfolding time of origin. If, on the other hand, the magnetic minerals can be shown to be detrital, a depositional remanent magnetization (DRM) would be considered. However, a true DRM is obviously not possible at all sites because of demonstrated postfolding origin of stable magnetization.

The magnetic mineralogy of the limestones was inferred from the characteristics of remanent magnetization of whole rock samples. This procedure was necessitated by the difficulty of extracting sufficient quantities of the magnetic minerals for Curie temperature determination. Ore microscope observations of polished sections also were not particularly helpful and revealed only the occasional presence of highly reflecting grains of pyrite, up to about $1 \mathrm{~mm}$ in size. The magnetic minerals in the limestone are evidently very finely divided, or larger grains are sparsely distributed in the limestone to escape detection in the sections examined.

\section{IRM Acquisition}

Isothermal remanent magnetization (IRM) acquisition curves can be used to characterize the bulk remanent coercivity spectra [Dunlop, 1972]. Certain magnetic minerals, such as magnetite and maghemite, typically have coercivities less than

TABLE 2. Summary of VRM Acquisition Experiments in $H=1$ Oe

\begin{tabular}{|c|c|c|c|}
\hline Sample & $\begin{array}{c}\text { VRM } \\
\text { hours }), 11,400 \\
\left(0^{-8} \mathrm{G}\right.\end{array}$ & NRM, $10^{-\bullet} \mathrm{G}$ & VRM/NRM \\
\hline \multicolumn{4}{|c|}{ Group A } \\
\hline A-5A & 4.54 & 3.72 & 1.20 \\
\hline LA-16A & 1.58 & 1.15 & 1.37 \\
\hline LC-69A & 1.88 & 1.46 & 1.29 \\
\hline UB-13A & 5.36 & 2.96 & 1.81 \\
\hline E-2A & 4.69 & 2.77 & 1.69 \\
\hline \multicolumn{4}{|c|}{ Group B } \\
\hline A-5B & 5.18 & 4.24 & 1.22 \\
\hline LA-16B & 1.04 & 0.89 & 1.17 \\
\hline LC-69B & 1.65 & 1.47 & 1.12 \\
\hline UB-13B & 5.32 & 2.33 & 2.28 \\
\hline E-2B & 5.72 & 3.25 & 1.76 \\
\hline
\end{tabular}

In group A, VRM acquisition is from the demagnetized (400-Oe af) state, and in group $B, V R M$ acquisition is in the presence of NRM. 

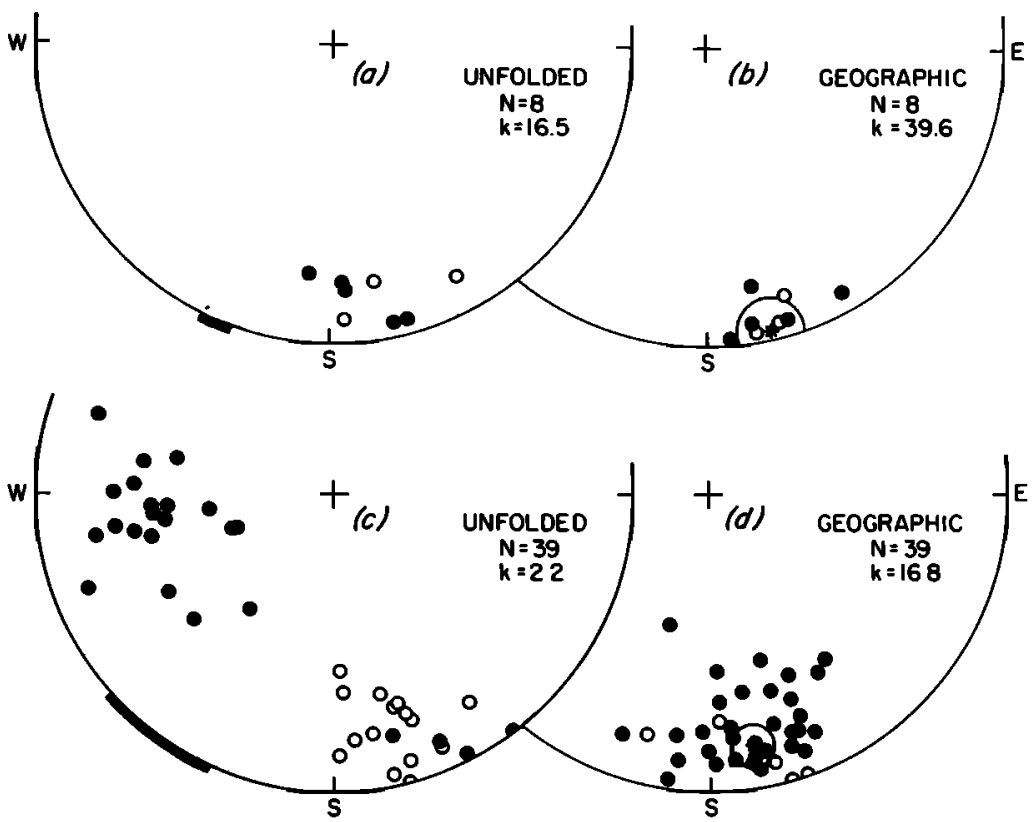

Fig. 7. Directions of NRM after af demagnetization to 300 Oe of samples from the fold at $(a, b)$ Clarksville and $(c, d)$ Leeds Gorge. Solid (open) symbols are plotted on the lower (upper) hemisphere of equal-area projections. Solid bars along the perimeter of the equal-area projections in Figures $7 a$ and $7 c$ indicate the ranges of measured bedding strikes and approximate the trends of the fold axis. Stars in Figures $7 b$ and $7 d$ represent the calculated mean directions of sample magnetizations with the associated circles of $95 \%$ confidence; $k$ is Fisher's precision parameter.

a few thousand oersteds, while others, such as hematite and goethite generally have much higher coercivities. Although measures of remanent coercivity alone are not very diagnostic of particular magnetic minerals, for example, because of grain size effects and overlapping coercivities of different magnetic minerals, they do provide some constraints in conjunction with other data in interpreting the magnetic mineralogy of rock samples.

The IRM acquisition curves for a set of limestone samples are similar in shape even though the maximum IRMs differ in

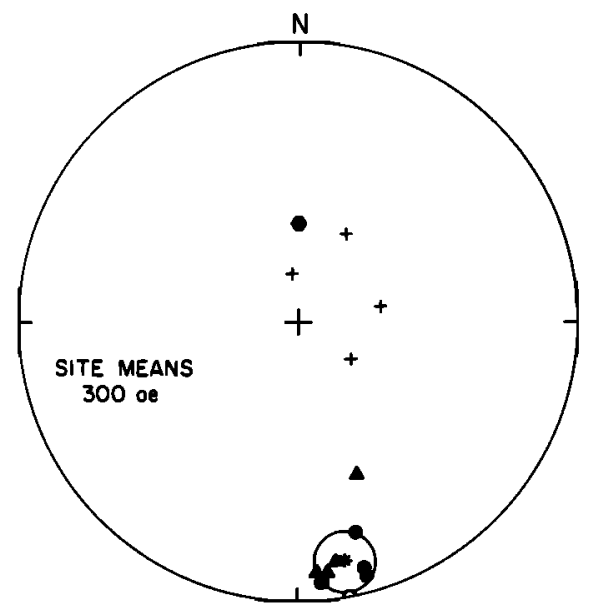

Fig. 8. Site mean directions after $300-0 e$ af demagnetization of Onondaga limestone, plotted without correction for bedding tilt on equal-area projection. The hexagon represent the direction of present geomagnetic dipole fields for the sampling area. Small pluses represent the sites (E, F, G, and $H$ ) with unresolved, composite magnetization (see text), which are not included with the sites shown by circles (tilted bedding) and triangles (flat-lying bedding) in calculation of the formation mean direction, plotted as the star with associated circle of $95 \%$ confidence. All directions are plotted on the lower hemisphere of projection except for the open circle, which is on the upper hemisphere. intensity by nearly 1 order of magnitude, presumably because of variations in concentration of the magnetic minerals (Figure 10). Each curve shows a large initial increase in IRM to fields of about $2 \mathrm{kOe}$, followed by a more gradual increase to $4 \mathrm{kOe}$, the highest direct field used in the experiments. The magnetic mineralogy of these limestones is therefore dominated by a component with coercivities less than a few kilooersteds. The

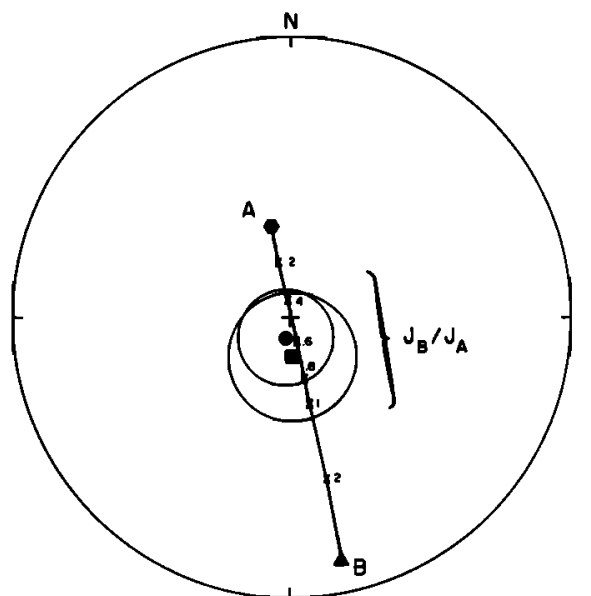

Fig. 9. Illustration of model to account for steep NRM directions in Onondaga limestone as the vector sum of two magnetizations, one a viscous component along the present geomagnetic field $(A)$ for the sampling area, and the other the stable component $(B)$ of ancient origin. Varying the relative contribution of the two vector magnitudes $\left(J_{B} / J_{A}\right)$ gives resultant directions along a great circle path joining the two component vectors $(A$ and $B$ ); directions corresponding to some values of $J_{B} / J_{A}$ are shown by small crosses. The solid circle is the mean NRM direction of the Onondaga formation and the associated circle of angular dispersion $\left(\Theta_{\mathrm{es}}=13.4^{\circ}\right)$; the solid square is the mean NRM direction calculated by Cox and Doell [1960] from the original data of Graham [1956] for Onondaga limestone with the associated circle of angular dispersion $\left(\Theta_{\theta 3}=18.6^{\circ}\right)$. All directions are plotted on the lower hemisphere of equal-area projection. 


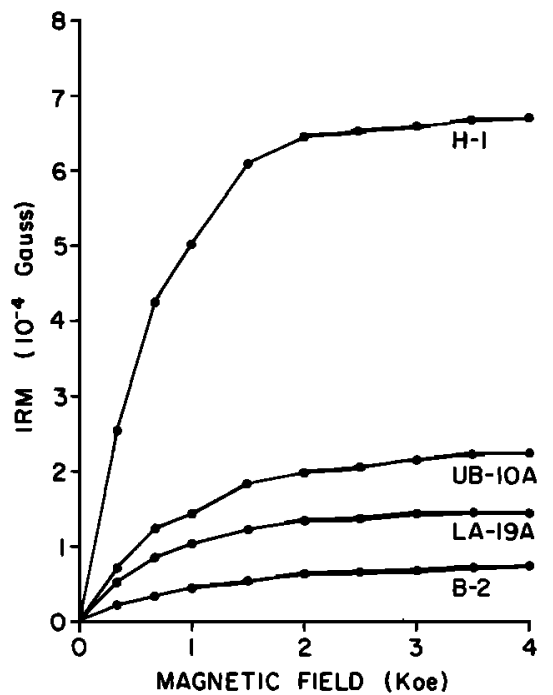

Fig. 10. IRM acquisition curves for samples of Onondaga limestone.

flattening of the IRM acquisition may indicate an approach to saturation of this component by $4 \mathrm{kOe}$, although it is possible that the small continued increase in IRM from 2 to $4 \mathrm{kOe}$ is due to the presence of a subsidiary component of higher coercivity. In either case the presence of the dominant lowercoercivity IRM component is consistent with the generally low stability of the NRM, so it is reasonable to assume that the NRM is largely controlled by this component.

\section{Blocking Temperatures}

Thermal demagnetization curves of NRM and IRM of representative samples are compared in Figure 11. The blocking temperature curves of IRM are essentially the same for all samples and are characterized by a smooth decrease to a maximum blocking temperature falling in a narrow range between $505^{\circ}$ and $535^{\circ} \mathrm{C}$ (Figure $11 \mathrm{~b}$ ). In lieu of high-field thermomagnetic curves which give diagnostic Curie temperatures the magnetic mineralogy can nevertheless be con- strained by blocking temperature data, bearing in mind that the maximum blocking temperature may be less than but cannot exceed the Curie temperature of a given magnetic mineral. If the magnetic properties of the Onondaga limestone are attributed to a single, dominant magnetic mineral, which is suggested by the absence of kinks in the sample blocking temperature spectra, then several common magnetic minerals with Curie temperatures less than the maximum observed blocking temperature are not likely to be important constituents. For example, although geothite has been found to be an important magnetic mineral in some upper Jurassic limestones from Europe [Heller, 1978], the low blocking temperatures, typically less than $100^{\circ} \mathrm{C}$, and very high coercivities that characterize geothite are not observed in the Onondaga limestone. Iron sulphide minerals are often present in limestones, and pyrite is identified in several samples of the Onondaga limestone. However, pyrrhotite, the only iron sulphide which is ferrimagnetic, has a Curie temperature of only about $300^{\circ} \mathrm{C}$. Maghemite is also not likely to be present in significant amounts on account of its metastable behavior, which causes it to invert to hematite, with a substantial reduction in magnetization, usually at moderate temperatures, well below $500^{\circ} \mathrm{C}$ [Readman and $O^{\prime} R e i l l y, 1972$ ]. While it is possible that the observed blocking temperatures have been elevated as the result of alteration of the original magnetic mineralogy during heating in air, this is not considered likely because of the very similar thermal demagnetization characteristics of all the samples studied and because the coercivities of IRM can be essentially the same before and after heating (e.g., for sample DOE$1 \mathrm{~A}$ the median destructive field of IRM is 286 Oe initially and $305 \mathrm{Oe}$ after heating to $555^{\circ} \mathrm{C}$ ). On the other hand, the blocking temperature data do not exclude hematite or high Curie point hema-ilmenites, but these magnetic minerals generally possess very high coercivities for which there is little evidence in these rocks. In the absence of direct observations the most reasonable interpretation of the blocking temperature data is a magnetic mineralogy dominated by some form of magnetite. This interpretation is also consistent with the IRM acquisition characteristics which show a large contribution from a component with coercivities appropriate to magnetite. Although

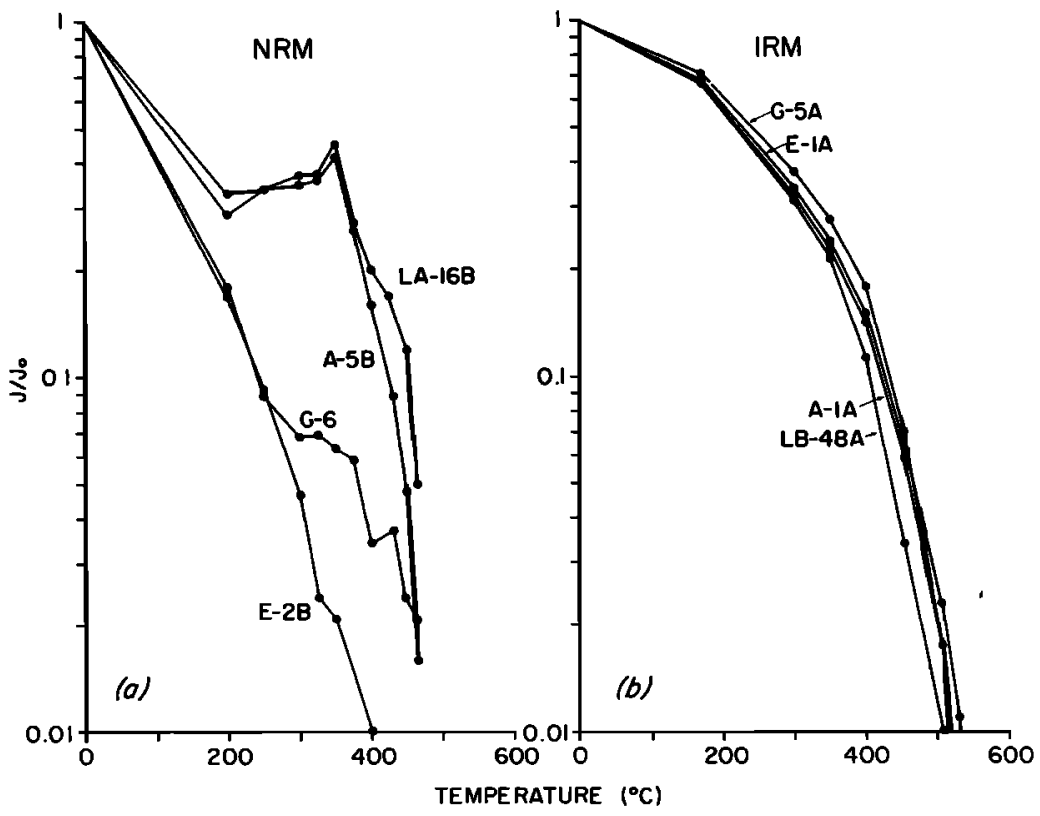

Fig. 11. Normalized thermal demagnetization curves for (a) NRM and (b) IRM of samples of Onondaga limestone. 
the maximum blocking temperatures that are observed are appreciably below the Curie temperature of $580^{\circ} \mathrm{C}$ for pure magnetite, this can be due to titanium in the magnetite lattice. This magnetic mineral may be related to the presence of volcanic ash (Tioga bentonite) in these limestones.

The blocking temperature spectra of NRM are more variable than those of IRM and are related to the paleomagnetic direction. In samples which give a shallow, southerly direction after either af or thermal demagnetization, there is a plateau in the demagnetization curves between 200 and $350^{\circ} \mathrm{C}$ after an initial decrease; the stable component of magnetization has blocking temperatures that range to almost $500^{\circ} \mathrm{C}$ (Figure $11 a$ ). In contrast, many of the samples from the four sites which give unreliable paleomagnetic data show a steady decrease in $\mathrm{NRM}$ to about $400^{\circ} \mathrm{C}$, where the magnetization disappears (i.e., sample E-2B (Figure 11a)). For the most part this magnetization is along the present magnetic field and is of viscous origin (see Figure $5 d$ ). Thermal demagnetization curves of a few samples from these four sites are of an intermediate nature: There is a large initial decrease in remanence to about $300^{\circ} \mathrm{C}$ as the viscous component is removed, followed by a more gradual reduction and eventual disappearance of the sample magnetization before $500^{\circ} \mathrm{C}$ (sample G-6 (Figure $11 a)$ ). These few samples give the same shallow, southerly direction as is found in the other, more reliable sites. Although it was not possible to determine accurately the maximum blocking temperature of this component because of the very weak moments, it appears to be uniform from sample to sample and about the same as that for the IRM, that is, close to $500^{\circ} \mathrm{C}$. Therefore the NRM appears also to be carried by the same magnetic mineral identified in the IRM experiments, magnetite, with the steps in the sample NRM blocking temperature distribution most likely reflecting different magnetization processes.

\section{Magnetic Grain Size}

The characteristic magnetic grain size can be determined qualitatively by following a modification of the method of Lowrie and Fuller [1971]. In its simplest form the method is to compare the relative stability to alternating fields of low-field thermoremanent magnetization and a high-field IRM: stability of TRM greater (less) than that of IRM is diagnostic of finegrained (coarse-grained) magnetic remanence carriers in the sample tested. Dunlop et al. [1973] and Johnson et al. [1975] showed that anhysteretic remanent magnetization (ARM) can be substituted for TRM in applying the Lowrie-Fuller test, and this modification of the test is followed here. After progressive af demagnetization of NRM a set of specimens was given an ARM in a 1-OE bias field coaxial with a $2000-0$ e af. This remanence was af demagnetized, as was a subsequently induced (in a direct field of $2000 \mathrm{Oe}$ ) IRM. Normalized af demagnetization curves of NRM, ARM, and IRM are shown for four specimens in Figure 12.

The relative stabilities of NRM, IRM, and ARM are uniformly alike in all samples measured: IRM is always found to be more stable against alternating fields than ARM, while NRM typically is the least stable. For eight specimens (from eight different sites) the median destructive field for IRM is $291 \pm 11 \mathrm{Oe}$, for ARM is $205 \pm 37 \mathrm{Oe}$, and for NRM is $69 \pm$ $40 \mathrm{Oe}$. The low coercivity of NRM is largely due to the removal of a large viscous magnetization at low fields. According to the criteria of Johnson et al. [1975] the higher stability of IRM with respect to ARM is indicative of a dominant, coarse-
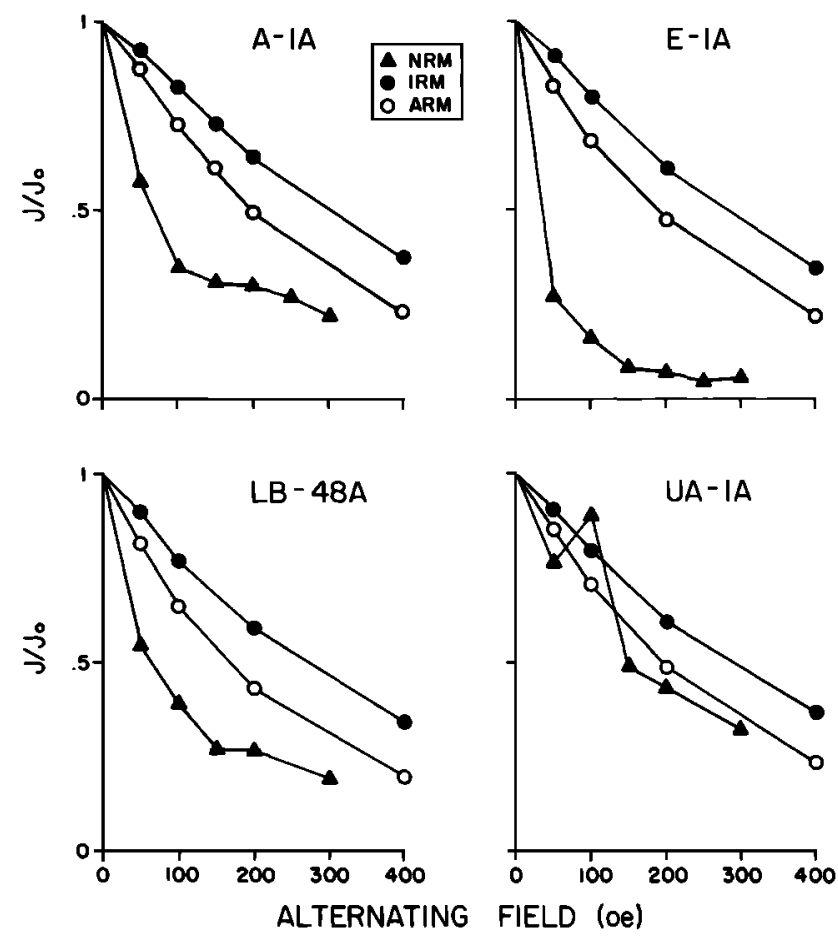

Fig. 12. Comparison of af demagnetization curves of NRM, IRM, and ARM for samples of Onondaga limestone.

grained magnetic mineralogy; for magnetite this implies typical grain sizes in excess of about $20 \mu \mathrm{m}$.

The indication of a coarse-grained magnetic mineral is not unexpected considering the low stability of NRM but is nevertheless puzzling in light of the difficulty in detecting magnetic grains in polished sections, which would imply very fine grain sizes, below the limit of resolution of the light microscope. The same apparent paradox was encountered by McElhinny and Opdyke [1973] in the Ordovician age Trenton limestone. It is possible that the test criteria for characteristic magnetic grain sizes suggested by Johnson et al. [1975] are inappropriate for these rocks. For example, an apparent coarse-grained indication in relative stabilities of ARM and IRM may reflect grains just larger than the single-domain to multidomain transition, or about $1 \mu \mathrm{m}$ or less for magnetite, rather than the transition from pseudosingle domain to pure multidomain, or about $20 \mu \mathrm{m}$, as is suggested by the experimental work on synthetic samples. The magnetic mineralogy of these shallow water limestones may also be more complex, and some additional, as yet unidentified magnetic mineral could be present to give an anomalous result in the indirect test for magnetic grain size. Alternatively, there may be relatively few but large magnetic grains which can dominate a very fine grain size fraction in many of the bulk magnetic properties but could escape optical detection by virtue of their very limited numbers in these weakly magnetized rocks. It is not possible to distinguish on the basis of the available data which, if any, of these hypotheses is correct, and the magnetic mineralogy and grain size in the limestones must therefore be considered to be not well resolved.

\section{ANISOTROPY OF MAGNETIC SUSCEPTIBILITY}

The measurement of anisotropy of magnetic susceptibility may be used to estimate the preferred grain orientation in sedimentary rocks. In general, the maximum susceptibility of an irregular magnetic grain lies along its greatest dimension, 
and minimum susceptibility is across it. A rock containing a small proportion of such isolated grains which have some preferred orientation of short and long axes will have directional differences in susceptibility that define a magnetic fabric, representing the vector sum of the anisotropies of all the contributing grains. A primary magnetic fabric is associated with conditions at the time of deposition and is generally characterized by minimum susceptibility aligned about the normal to the bedding [Hamilton and Rees, 1970]. Subsequent deformation of the sediment can modify the primary fabric and give a pattern of anisotropy that is systematically related to the structural setting [Graham, 1967]. Since measurement of remanent magnetization gives the statistical alignment of grain magnetic moments, while susceptibility anisotropy is a measure of preferred alignment of grain shape, it is of interest to compare the two parameters particularly because the same magnetic mineralogy may be involved.

The susceptibility anisotropy of samples from selected sites was measured with a low-field torque instrument, similar in design and operation to that described by King and Rees [1962]. The method of measurement and computation of anisotropy [Granar, 1958] assume that the susceptibility of a sample can be approximated by a second-rank symmetric tensor $K i j$ which linearly relates the magnetization $J i$ induced in a specimen by a field $H j: J i=K i j H j$.

Five torque readings at $45^{\circ}$ increments about each of three orthogonal axes relative to the specimen were taken in an alternating field of 70 Oe rms. More data are produced than are needed to describe the susceptibility anisotropy, and the best data values are found by a least squares fit. The differences between the optimized values for the susceptibility tensor and the original readings are calculated, and an estimate of data reliability is made from the root-mean-square value of these residuals. For the majority of the specimens measured, the rms residual values were typically small, and a level of $10 \%$ of the rms optimized values was arbitrarily chosen for specimen rejection. The generally low residuals support the assumption that the susceptibilities are adequately represented by a second-order tensor (triaxial ellipsoid), which describes a representative orientation for all the magnetic grains in a sediment. Conversely, the high measurement errors for the specimens that were rejected from further consideration can stem from susceptibilities that are more complex than second order, from very weak anisotropies, or a combination of these and other causes [King and Rees, 1962].

\section{Anisotropy Results}

The directions of the principal axes of maximum $\left(K_{\max }\right)$, intermediate $\left(K_{\mathrm{Int}}\right)$, and minimum $\left(K_{\min }\right)$ susceptibility determined for specimens from an exposure of Onondaga limestone in Ulster County Quarry are plotted in Figure 13a. The limestone at this locality is essentially flat lying (dips $<5^{\circ}$ ) and shows no visible evidence of tectonic disturbance. The orientation of the principal susceptibility axes is characteristic of a primary magnetic fabric: the $K_{\min }$ directions are clustered normal to the bedding, while the $K_{\operatorname{lnt}}$ and $K_{\max }$ directions are distributed within the horizontal plane. Such a magnetic fabric is reasonably attributed to gravitational couples bringing the long axes of magnetic grains close to the horizontal plane at the time of deposition, although subsequent compaction of the sediment may have also played a role.

While an original depositional fabric is evidently preserved in the flat-lying beds at Ulster Quarry, the magnetic fabric of specimens taken from the limbs of an asymmetric synclinal fold at Leeds Gorge is clearly in response to the deformation (Figures $13 b$ and $13 c$ ). In the steeply dipping to overturned limb of the fold the $K_{\max }$ axes are very nearly parallel to the fold axis, while the $K_{1 \mathrm{nt}}$ and $K_{\mathrm{m} / \mathrm{n}}$ axes are well dispersed in the perpendicular plane (Figure $13 \mathrm{c}$ ). In the more moderately inclined (dips about $45^{\circ}$ ), upright limb of the fold the characteristics of the magnetic fabric are intermediate between the primary fabric of the flat-lying beds and the fabric that is strongly related to the folding in the overturned limb of the fold: The $K_{\min }$ axes are rotated from the vertical and begin to form a girdle in a plane perpendicular to the fold axis, but neither the $K_{\max }$ nor the $K_{\text {int }}$ appears to form any systematic grouping or trend (Figure 13b). Moreover, the susceptibility of only six of the 18 specimens measured from the upturned limb are well represented (residuals less than $10 \%$ of optimum values) by a second-order tensor; this compares to 17 of 19 from

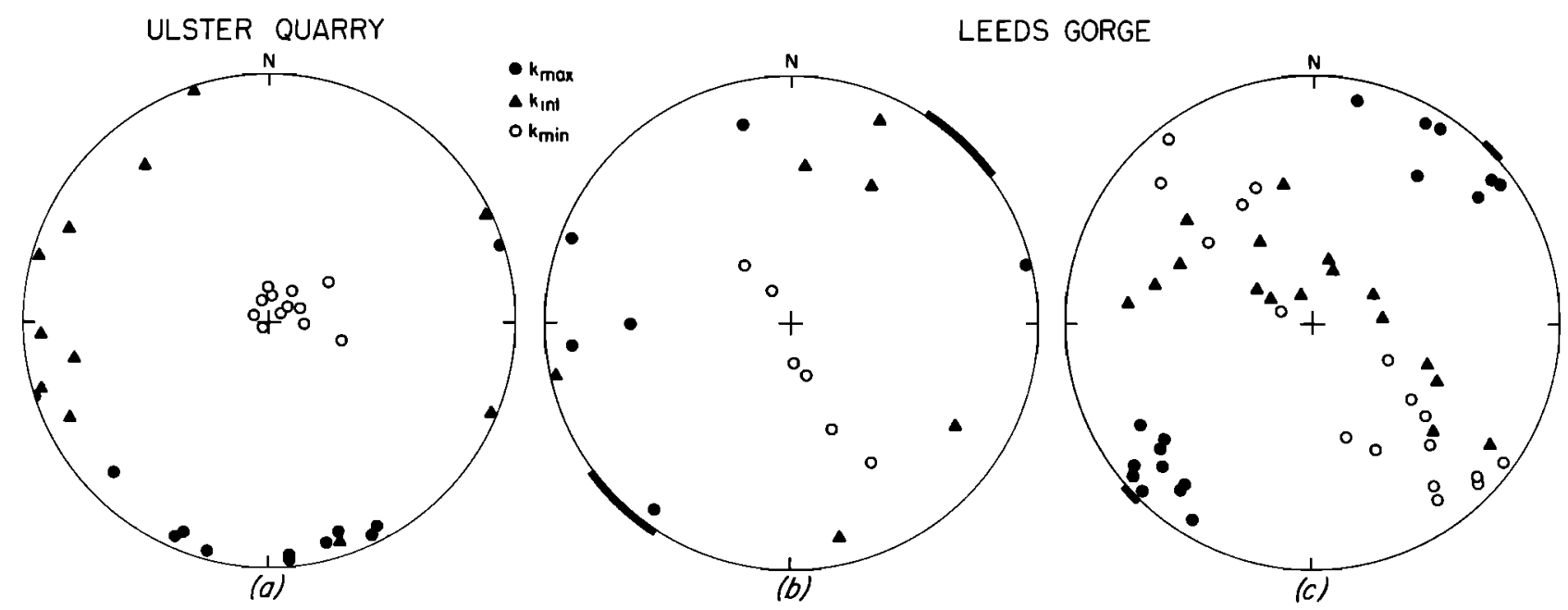

Fig. 13. Directions of maximum $\left(K_{\max }\right)$, intermediate $\left(K_{\mathrm{tnt}}\right)$, and minimum $\left(K_{\mathrm{m} 1 \mathrm{n}}\right)$ magnetic susceptibility axes of Ondondaga limestone samples plotted with respect to bedding on lower hemisphere of equal-area projections. (a) Flat-lying beds exposed near Kingston, New York. (b) Upright limb and (c) steeply inclined to overturned limb of syncline exposed near Leeds, New York. The solid bars along the perimeter of Figures $13 b$ and $13 c$ are measured bedding strikes which approximate the trend of the fold axis. 


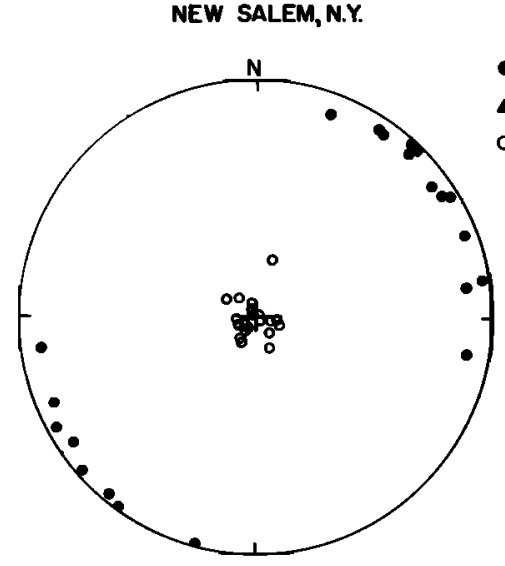

(a)
CLARKSVILLE, N.Y

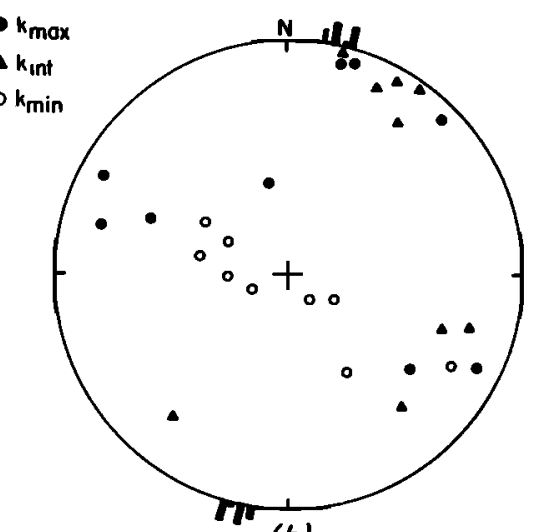

(b)

Fig. 14. Direction of maximum $\left(K_{\max }\right)$, intermediate $\left(K_{1 n t}\right)$, and minimum $\left(K_{\min }\right)$ magnetic susceptibility axes of Onondaga limestone samples plotted with respect to bedding on the lower hemisphere of equal-area projections. $(a)$ Flatlying beds. (b) Small penecontemporaneous fold with bedding strikes indicated along the perimeter of the projection (redrawn from figures of Graham [1967]).

the overturned limb and 12 of 14 from the flat-lying beds. These observations are reasonably accounted for by postulating the presence of two superimposed fabrics in most of the samples from the upright limb: a vestigial primary fabric and an incipient deformation fabric. The combined fabrics cannot be resolved by a simple second-order tensor, whereas in the specimens from the overturned limb the fabric has evidently been more completely modified by the deformation and is dominant. It is worth mentioning that at none of the localities did the anisotropy exceed a few percent of the average bulk susceptibility, and no deflection of the remanence vector is therefore expected from this cause.

Graham [1967] previously measured the susceptibility anisotropy of the Onondaga limestone at two localities. In flatlying beds exposed near New Salem, New York, the $K_{\min }$ axes are well grouped around the vertical, and the $K_{\max }$ axes are distributed in the bedding plane (Figure 14a), exactly what we find in flat-lying beds at Ulster County Quarry (Figure 13a) and which is characteristic of a primary or depositional magnetic fabric. Graham [1967] also measured the susceptibility anisotropy of specimens taken from a small fold exposed near Clarksville, New York. The fold, less than $1 \mathrm{~m}$ across, is believed to have been generated by penecontemporaneous deformation and is the same fold that we sampled for magnetic remanence studies. The anisotropy measurements (Figure 14b) yielded two principal results: (1) either the $K_{\max }$ or the $K_{\operatorname{lnt}}$ axes are nearly parallel to the fold axis and (2) the other axes are dispersed in a plane normal to the fold axis. These observations are very similar to those that we make here for the largerscale fold at Leeds Gorge. Graham [1967] interpreted the anisotropy pattern from the Clarksville fold as reflecting the rotation of magnetic grains within the plastic, unconsolidated sediment, in response to the stresses that eventually produced the structure. Evidently, the same history may be applicable to the Leeds Gorge fold but on a larger scale.

\section{Discussion}

The nine site mean stable directions of magnetization, without correction for bedding tilt, give a mean paleomagnetic (north) pole position near latitude $40^{\circ} \mathrm{N}$, longitude $121^{\circ} \mathrm{E}$ (Table 1). This pole position corresponds reasonably well with other Devonian poles from cratonic North America, for ex- ample, from the Delaware and Columbus limestones of Ohio [Martin, 1975] and from the Catskill red beds of New York [Kent and Opdyke, 1978] (Figure 15). However, the Onondaga pole, together with the other North American Devonian poles cited above, falls near the well-known Permian pole position for North America [e.g., Van der Voo and French, 1974]. For a

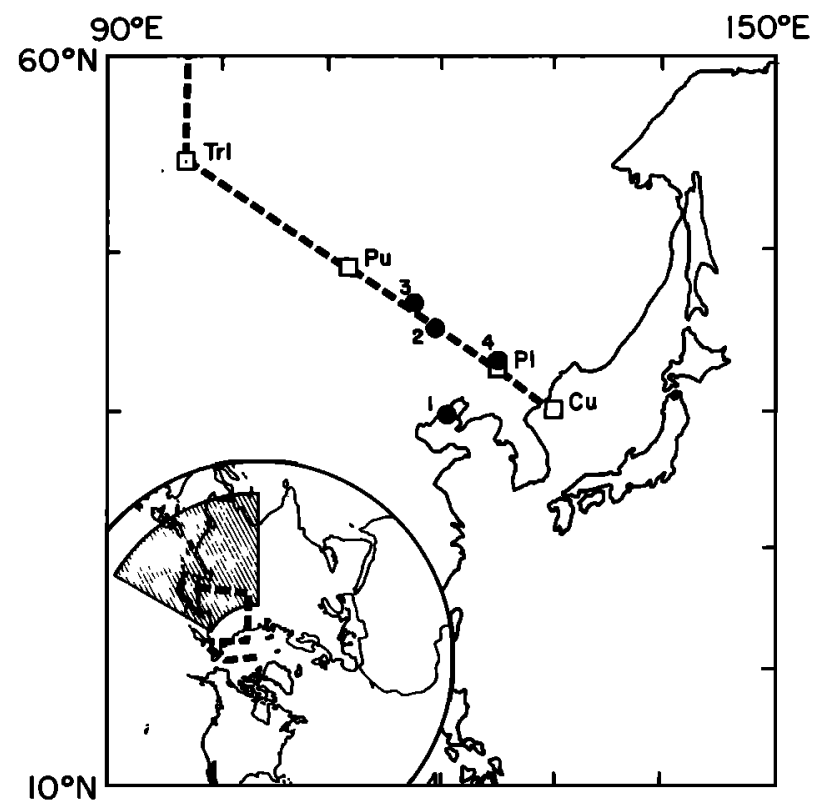

Fig. 15. Paleomagnetic (north) pole positions for Devonian age rocks from cratonic North America are shown by solid circles: 1 is Onondaga (this study); 2 is Catskill red beds, New York [Kent and Opdyke, 1978]; 3 is Columbus and Delaware limestone (combined pole, reversed directions [Martin, 1975]); and 4 is Catskill red beds, Pennsylvania (R. Van der Voo, personal communication, 1978). These are compared to a segment of the apparent polar wander path for North America (dashed line) [from Van der Voo and French. 1974], showing Upper Carboniferous $(\mathrm{Cu})$, Lower and Upper Permian (Pl and $\mathrm{Pu}$, respectively), and Lower Triassic (Trl) mean pole positions (open squares). The inset shows the Upper Carboniferous to Recent apparent polar wander path for North America [from Van der Voo and French, 1974] plotted on a north polar projection of the continents; the hachured area is the part shown expanded in Mercator projection in the main part of the figure. 
variety of reasons, discussed by Kent and Opdyke [1978], the cratonic North American Devonian pole is believed to be in fact nearly coincident with the Permian position, and this coincidence is not due to a widespread remagnetization of the Devonian rock units in question. However, in light of the postfolding time of origin of the stable remanence in the Onondaga limestone, it is not obvious if this magnetization was also acquired in the Devonian rather than later, say, in the Permian.

Consideration of the limestone magnetic fabrics may shed some light on this question. Graham [1967] postulated that the magnetic susceptibility anisotropy pattern of sediments can by systematically influenced as the result of deformation in a plastic condition, prior to lithification. The magnetic fabric measured by Graham in the small fold at Clarksville certainly lends itself to this interpretation, since the deformation is evidently penecontemporaneous, occurring soon after deposition of the beds. The rock magnetic studies suggest a magnetic mineralogy dominated by some form of magnetite which because of its high susceptibility and strong shape-dependent anisotropy is considered the most likely source of the observed magnetic fabric by dimensional grain orientation in the rock. Since the observed anisotropy pattern in this small fold appears to be closely related to the penecontemporaneous deformation, the magnetic grains which carry the magnetic anisotropic properties are therefore most likely of detrital origin, or if authigenic, then formed very soon after deposition. A similar argument can be advanced for the flat-lying beds, since they appear to carry a primary magnetic fabric, evidently preserved from the time of their deposition.

In contrast to the deformation at Clarksville, the time of folding at the Leeds Gorge locality (part of the narrow 'Little Mountains' fold belt of the Hudson River Valley) is not well constrained stratigraphically and is generally thought to be associated with either the Acadian orogeny in the Devonian or the Alleghenian orogeny in the late Paleozoic [Schuchert and Longwell, 1932; Woodward, 1957; Rodgers, 1967]. Consequently, the time of origin for the susceptibility anisotropy which is related to the rock deformation is also difficult to ascertain. It can be argued that the similarity in magnetic fabrics in the penecontemporaneous fold at Clarksville and the larger fold exposed relatively nearby at Leeds Gorge reflects a similar style of deformation and acquisition of magnetic properties. This would imply that the deformation at Leeds Gorge also occurred while the sediment was still not lithified. Deformation soon after deposition, during the Acadian orogeny, is an obvious and likely possibility, since only a short time interval is required for the sediments to remain unlithified. However, the diagenetic history of the limestones is poorly known so that some involvement later in the Alleghenian orogeny cannot be precluded on the basis of this line of evidence.

Where they are isolated, the characteristic directions of magnetization from both the flat-lying and the deformed beds form a single well-grouped population that suggests a common time of origin. If the characteristic remanence is indeed carried by the same magnetic mineral that accounts for the susceptibility anisotropy of these rocks, then the magnetization at many of the sites also may originate from near the time of deposition. For the case of the penecontemporaneous fold, some of the magnetic particles, perhaps a fine-grain-size fraction, must have been free to realign in the paleomagnetic field for a time following deformation to give rise to the stable remanence that is preserved in the rocks. The acquisition mechanism can be considered a form of postdepositional
DR M [Irving and Major, 1964; Kent, 1973; Lbvlie, 1974], and a similar mechanism has been suggested as the process responsible for the stable magnetization in penecontemporaneous slump structures in the Ordovician Trenton limestone $[\mathrm{McEl}$ hinny and Opdyke, 1973]. The same process is applicable for the fold at Leeds Gorge, whereas for the flat-lying beds it is possible that they carry a true DRM which, however, is difficult to distinguish from a postdepositional DRM.

The pole position derived from the nine site mean characteristic directions may therefore be representative of the paleomagnetic field of North America for the Devonian, the age of the Onondaga limestone, and the probable age of its deformation, although this interpretation would obviously not be valid if the folding at Leeds Gorge proves to be Alleghenian or of late Paleozoic age. Moreover, it is feasible that the magnetic grains were free to realign in interstitial water of the sediment at all of the sites up until diagenesis was completed. The Onondaga limestone in the Hudson River Valley may well have become lithified early in its history, for example, as the result of emergence or change from the marine environment as evidenced by the presence of Middle to Upper Devonian terrestrial sediments of the Catskill group higher in the stratigraphic section. However, although such a transformation of unconsolidated carbonate sediments to limestone is considered an important limestone-forming process, the diagenetic history of carbonates can be sufficiently complex and varied [e.g., Bathurst, 1971] to allow the possibility for lithification, and the locking-in of the presumed postdepositional DRM, to occur much later in time.

To conclude, it appears that several important questions concerning the magnetization of the Onondaga limestone remain unanswered and will require additional study to resolve, for example, more detailed descriptions of magnetic mineralogy and grain size. It is also evident that the diagenetic history of limestones will need to be considered more fully in interpreting the origin and age of the characteristic magnetizations. An early diagenesis and acquisition of characteristic remanence is favored for the Onondaga limestone but is not proved. A critical experiment would be to determine if the Onondaga limestone has a prefolding characteristic remanence where it has been clearly affected by Alleghenian folding. What is, however, clear from the present study is that the near-vertical NRM directions reported by Graham [1956] and also found here in the Onondaga do not reflect a record of any paleomagnetic field of similar orientation. They are instead the resultant of a large viscous component along the present geomagnetic field and a shallow characteristic magnetization of Devonian to possibly Permian age. It is also apparent that the same kind of ambiguities in determining the magnetization age of the Onondaga may apply to other limestones, particularly the Ordovician Trenton limestone, which has similar magnetic properties.

Acknowledgments. I thank Terry Engelder and Neil Opdyke for critical review of the manuscript and $\mathbf{R}$. Van der Voo for his suggestion of the critical experiment mentioned in the discussion. Participation of Neil Opdyke and Carolyn Kent in the field sampling is also appreciated. This research was supported by the National Science Foundation under grant EAR 75-18955. Lamont-Doherty Geological Observatory contribution 2831 .

\section{REFERENCES}

Bathurst, R. G. C., Carbonate Sediments and their Diagenesis, 620 pp., Elsevier, New York, 1971.

Claesson, C., Swedish Ordovician limestones: Problems in clarifying 
their directions of magnetizations, Phys. Earth Planet. Interiors, 16. 65-72, 1978.

Cox, A., and R. R. Doell, Review of paleomagnetism, Geol. Soc. Amer. Bull., 7I, 645-768, 1960.

Creer, K. M., A review of paleomagnetism, Earth Sci. Rev., 6, 369$466,1970$.

Dunlop, D. J., Magnetic mineralogy of unheated and heated red sediments by coercivity spectrum analysis, Geophys. J. Roy. Astron. Soc., 27, 37-55, 1972.

Dunlop, D. J., J. A. Hanes, and K. L. Buchan, Indices of multidomain magnetic behavior in basic igneous rocks: Alternating-field demagnetizations, hysteresis, and oxide petrology, J. Geophys. Res., 78, 1387-1393, 1973.

Fisher, R. A., Dispersion on a sphere, Proc. Roy. Soc. London, Ser. A, 217, 295-305, 1953.

Graham, J. W., Rock magnetism and the earth's magnetic field in Paleozoic time, J. Geophys. Res., 59, 215-222, 1954.

Graham, J. W., Paleomagnetism and magnetostriction, J. Geophys. Res., 61, 735-739, 1956

Graham, J. W., Significance of magnetic anisotropy in Appalachian sedimentary rocks, in The Earth Beneath the Continents, Geophys. Monogr. Ser., vol. 10, edited by J. S. Steinhart and T. J. Smith, pp. 627-648, AGU, Washington, D. C., 1967.

Granar, L., Magnetic measurements on Swedish varved sediments, Ark. Geofys., 3(1), 1-40, 1958.

Hamilton, N., and A. I. Rees, The use of magnetic fabric in paleocurrent estimation, in Paleogeophysics, edited by S. K. Runcorn, pp. 445-464, Academic, New York, 1970.

Heller, F., Rockmagnetic studies of Upper Jurassic limestones from southern Germany, J. Geophys., 44, S25-544, 1978.

Irving, E., and A. Major, Post-depositional remanent magnetization in a synthetic sediment, Sedimentology, 3, 135-143, 1964.

Johnson, H. P., W. Lowrie, and D. V. Kent, Stability of anhysteretic remanent magnetization in fine and coarse magnetite and maghemite particles, Geophys. J. Roy. Astron. Soc., 4I, 1-10, 1975.

Kent, D. V., Post-depositional remanent magnetisation in deep-sea sediment, Nature, 246, 32-34, 1973.

Kent, D. V., and N. D. Opdyke, Paleomagnetism of the Devonian Catskill red beds: Evidence for motion of coastal New EnglandCanadian Maritime region relative to cratonic North America, $J$. Geophys. Res., 83, 4441-4450, 1978.

King, R. F., and A. I. Rees, The measurement of the anisotropy of magnetic susceptibility of rocks by the torque method, J. Geophys. Res., 67, 1565-1572, 1962.

Løvlie, R., Post-depositional remanent magnetization in a redeposited deep-sea sediment, Earth Planet. Sci. Lett., 21, 315-320, 1974

Lowrie, W., and M. Fuller, On the alternating field demagnetization characteristics of multidomain thermoremanent magnetization in magnetite, J. Geophys. Res., 76. 6339-6349, 1971.

Martin, D. L., A paleomagnetic polarity transition in the Devonian Columbus limestone of Ohio: A possible stratigraphic tool, Tectonophysics, 28, 125-134, 1975.

McElhinny, M. W., Statistical significance of the fold test in paleomagnetism, Geophys. J., 8, 338-340, 1964.

McElhinny, M. W., and N. D. Opdyke, Remagnetization hypothesis discounted: A paleomagnetic study of the Trenton limestone, New York State, Geol. Soc. Amer. Bull., 84, 3697-3708, 1973.

Molyneux, L., A complete result magnetometer for measuring the remanent magnetization of rocks, Geophys. J. Roy. Astron. Soc., 10, 429, 1971.

Oliver, W. A., Coral faunas in the Onondaga limestones of New York, U.S. Geol. Surv. Prof. Pap., 400-B, 172-174, 1960.

Oliver, W. A., J. H. Johnsen, and J. B. Southard, The Onondaga limestone and the Schoharie formation in southeastern New York, in Guide Book to Field Trips: New York State Geological Association 34th Annual Meeting, edited by W. G. Valentine, pp. A 1-A24, New York State Geological Association, Port Jervis, N. Y., 1962.

Readman, P. W., and W. O'Reilly, Magnetic properties of oxidized (cation-deficient) titanomagnetites $(\mathrm{Fe}, \mathrm{Ti}, \square)_{3} \mathrm{O}_{4}, J$. Geomagn. Geoelec., 24, 69-90, 1972.

Rodgers, J., Chronology of tectonic movements in the Appalachian region of eastern North America, Amer. J. Sci., 265, 408-427, 1967.

Rudd, N., Some geologic factors bearing on the magnetization of the Onondaga limestone, M.A. thesis, Univ, of Minn., Minneapolis, 1955.

Schuchert, C., and C. R. Longwell, Paleozoic deformation of the Hudson Valley region, New York, Amer. J. Sci., 23, 305-326, 1932.

Van der Voo, R., and R. B. French, Apparent polar wandering for the Atlantic-bordering continents: Late Carboniferous to Eocene, Earth Sci. Rev., 10, 99-119, 1974.

Van der Voo, R., and R. B. French, Paleomagnetism of the Late Ordovician Juniata formation and the remagnetization hypothesis, J. Geophys. Res., 82, 5796-5802, 1977.

Woodward, H. P., Chronology of Appalachian folding, Amer. Ass. Petrol. Geol. Bull., 41, 2312-2327, 1957.

Zijderveld, J. D. A., A.C. demagnetization of rocks: Analysis of results, in Methods in Paleomagnetism, edited by D. W. Collinson, K. M. Creer, and S. K. Runcorn, pp. 254-286, Elsevier, New York, 1967.

(Received November 27, 1978;

revised January 1, 1979;

accepted February 13, 1979.) 